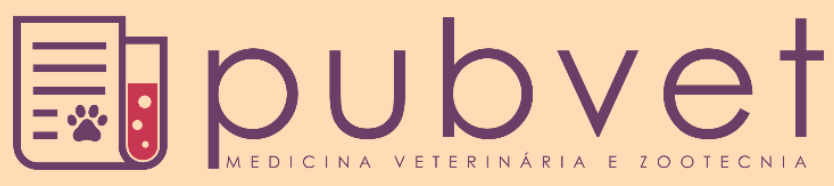

https://doi.org/10.31533/pubvet.v15n09a912.1-6

\title{
Uso de acupuntura, moxabustão, açúcar e rifamicina em ferida aberta de cão: Relato de caso
}

\author{
Guilherme Machado Hölzlsauer $^{1^{*}}$, Hudson Felipe Porto de Abreu ${ }^{2} \theta$, Daniele Amaro Pereira ${ }^{3}$, $^{\circ}$ \\ Andréa Cristina Scarpa Bosso Holzlsauer ${ }^{4} 0$
}

${ }^{I}$ Residente em Clínica Cirúrgica de Pequenos Animais da Universidade Federal do Tocantins, Araguaína, Tocantins, Brasil.

${ }^{2}$ Docente da Sociedade Cultural Educacional de Itapeva, Itapeva, São Paulo, Brasil.

${ }^{3}$ Médica Veterinária Autônoma, Marília, São Paulo, Brasil.

${ }^{4}$ Docente da Universidade Federal do Tocantins, Araguaína, Tocantins, Brasil.

*Autor para correspondência, E-mail: guilherme.holzlsauer@gmail.com

Resumo. A cicatrização de feridas cutâneas em cães é um processo visto rotineiramente. Atualmente, vários métodos de tratamento e cicatrização de feridas por segunda intenção têm sido estudados, de forma a obter uma cicatrização rápida e de qualidade, inclusive métodos alternativos de tratamento de feridas. Um cão andarilho foi atendido no Hospital Veterinário da Faculdade de Ciências Sociais e Agrárias de Itapeva, com sinais clínicos de acidente aracnídeo. Ao exame clínico observou-se que o membro pélvico direito se apresentava edemaciado e ulcerado. Após atendimento ambulatorial, o animal permaneceu internado durante dois dias e recebeu tratamento suporte com solução fisiológica a $0,9 \%$ associada à vitamina B12 e glicose 50\%; ceftriaxona, hidrocortisona e morfina. O animal continuou a ser cuidado no canil da mesma instituição, sendo feitos curativos diários durante 3 semanas e tratamento integrativo com Medicina Veterinária Tradicional Chinesa, com o uso de acupuntura e moxabustão indireta. Tais curativos eram constituídos de açúcar cristal misturado à rifamicina e bandagens não aderentes, pela manhã e à tarde, após as sessões de acupuntura e moxabustão indireta, que perduravam 10 minutos. Ao final das 3 semanas de tratamento a ferida apresentou regressão total, fechando-se por completo.

Palavras chave: Acidente aracnídeo, loxosceles, medicina veterinária tradicional chinesa, úlceras de pele

\section{Use of Acupuncture, moxibustion, sugar and rifamicyn to treat an open dog wound: Case report}

\begin{abstract}
Healing of cutaneous wounds in dogs is a routinely seen process. Nowadays, various methods of treating and healing wounds by second intention have been studied in order to obtain rapid and quality healing, including alternative methods of wound treatment. A walking dog was treated at the Veterinary Hospital of the Faculty of Social and Agrarian Sciences of Itapeva, with clinical signs of an arachnid accident. Clinical examination revealed that the right pelvic limb was swollen and ulcerated. After ambulatory care, the animal remained hospitalized for two days and received support treatment with $0.9 \%$ physiological solution associated with vitamin $\mathrm{B} 12$ and glucose 50\%; ceftriaxone, hydrocortisone and morphine. The animal continued to be cared for in the kennel of the same institution, with daily dressings for 3 weeks and integrative treatment with Traditional Chinese Veterinary Medicine using acupuncture and indirect moxibustion. These dressings were composed of crystal sugar mixed with rifamycin and non-adherent wafers, in the morning and afternoon, after the acupuncture and indirect moxibustion sessions, which lasted 10 minutes. At the end of the 3 weeks of treatment the wound presented total regression, closing completely.
\end{abstract}

Keywords: Arachnid accident, loxosceles, traditional chinese veterinary medicine, skin ulcers 


\section{Introdução}

Vários casos de acidentes com aranhas do gênero Loxosceles têm sido relatados por todo o mundo (Dantas et al., 2014). No Brasil, as notificações concentram-se nos Estados do Sul, particularmente no Paraná e Santa Catarina. Observa-se normalmente ferimentos em membros pélvicos, torácicos e troncos. Após 2-8 horas há dor e queimação, variando de leve a intensa (Silva et al., 2004). Isso seguido de aparecimento de bolhas de conteúdo seroso em 12-24h, que se pode tornar hemorrágica. Em 3 a 7 dias pode-se romper e causar úlcera cutânea (Chatzaki et al., 2012; Dantas et al., 2014; Ramos et al., 2015).

Segundo Cardot et al. (1995), a rifamicina é um antibiótico macro cíclico semissintético derivado da rifamicina natural B. Tem um grande espectro de ação bactericida em Gram-positivos e Gram-negativos (Abaylı et al., 2017). O açúcar além de modular a resposta inflamatória, é bem conhecido popularmente para tratamento de feridas nos trópicos (Mphande et al., 2007). Ele possui efeito bacteriostático e bactericida em feridas, devida à alta osmolaridade; essa característica pode ser somada a função bactericida da rifamicina e estes, em uma mistura, têm um efeito sinérgico (Cavazana et al., 2009; Rahal et al., 1979).

A acupuntura é uma técnica milenar da Medicina Tradicional Chinesa (MTC) (Hayashi \& Matera, 2005). Por sua fácil aplicação e boa tolerância do paciente, a moxaterapia e acupuntura são considerados métodos indicados para doenças crônicas, tratamento de feridas de difícil cicatrização, dores musculares e artropatias. Tanto a moxa quanto acupuntura tratam-se de terapias reflexas, em que o estímulo de uma área age sobre outra (Janssens, 2008; Scognamillo-Szabó \& Bechara, 2001; Wen, 2011; Xie \& Preast, 2012).

O objetivo deste trabalho é relatar um tratamento de ferida aberta em um cão, após provável picada de aranha, pelas práticas integrativas de uso de açúcar, rifamicina, moxabustão indireta e acupuntura.

\section{Relato de caso clínico}

Foi atendido no Hospital Veterinário da FAIT no dia 11 de novembro de 2016 um cão errante do campus da Faculdade de Ciências Sociais e Agrárias de Itapeva, sem raça definida, macho, de aproximadamente 12 anos e $15 \mathrm{~kg}$ com anorexia, apatia, edema de membro pélvico direito, úlcera cutânea profunda e granulomatosa, com visualização de tecido muscular e ósseo, extravasamento de líquido seroso pela lesão, lambedura no local da lesão, claudicação, dor e reflexo de propriocepção ausente no pé deste mesmo membro.

Testemunhas relataram a presença deste edema no membro há aproximadamente uma semana, que estava ulcerado somente há 24 horas. Ao exame clínico, observou-se hipertermia $\left(39^{\circ} \mathrm{C}\right)$, leve desidratação, frequência cardíaca de 113 batimentos por minuto e frequência respiratória de 40 movimentos por minuto. Pelas características da lesão, suspeitou-se de acidente aracnídeo.

$\mathrm{O}$ animal ficou internado no canil do hospital veterinário durante dois dias. No primeiro dia recebeu fluidoterapia com cloreto de sódio $0,9 \%$ associado à vitamina B12 e glicose $50 \%$. Também recebeu ceftriaxona $30 \mathrm{mg} / \mathrm{kg}$, hidrocortisona $50 \mathrm{mg} / \mathrm{kg}$ por via intravenosa e morfina $0,5 \mathrm{mg} / \mathrm{kg}$ por via intramuscular. No segundo dia o animal ainda apresentava apatia e hiporexia, sendo então realizada fluidoterapia com cloreto de sódio $0,9 \%$ associado à vitamina B12 e glicose a 50\%. Foi administrado novamente hidrocortisona $50 \mathrm{mg} / \mathrm{kg}$ e tramadol $3 \mathrm{mg} / \mathrm{kg}$, por via intravenosa. Por via intramuscular foi administrado penicilina $20.000 \mathrm{UI} / \mathrm{kg}$.

Realizaram-se então curativos diários, durante três semanas, contendo uma mistura de rifamicina e açúcar cristal, junto à bandagem pela manhã. À tarde eram realizadas sessões diárias de moxabustão indireta com bastão de moxa de Artemisia vulgaris sobre a ferida por 10 minutos e sessões concomitantes de 10 minutos de acupuntura com agulhas 0,25 x $30 \mathrm{~mm}$ nos acupontos BP6, VG20, cerco de dragão e pontos Bafeng, recolocando os curativos com rifamicina e bandagem. Duas vezes por semana eram acrescentados nas sessões de acupuntura os pontos R1 e o cinturão renal (VG4, B23, B52, VB25).

\section{Discussão}

Durante a primeira semana de tratamento, o animal apresentava claudicação e impotência funcional do membro e não apoiava o membro pélvico acometido. Já na segunda semana de tratamento, o animal apoiava o membro, mas não havia reflexo proprioceptivo. O reflexo de propriocepção foi reestabelecido na terceira semana de tratamento, coincidindo com a oclusão da ferida. Com a utilização combinada das 
técnicas de acupuntura, moxabustão e os curativos com açúcar misturado à rifamicina, a ferida fechou rapidamente, iniciando-se a formação de tecido de granulação a partir do $4^{\circ}$ dia de tratamento e ocludindo completamente após três semanas de tratamento (Figura 1).

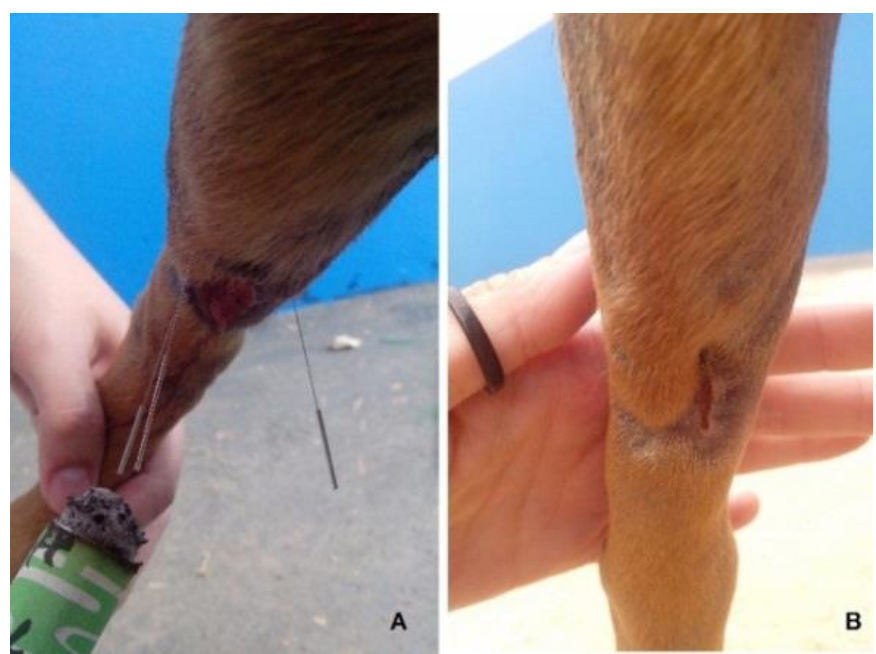

Figura 1. Tratamento de ferida com acupuntura e moxabustão. Em A, Sessão de acupuntura e moxabustão indireta na primeira semana de tratamento. Observa-se que o membro já não está edemaciado. Em B Ferida no começo da terceira semana de tratamento.

Tanto a lesão, como os sinais clínicos de acidente aracnídeo observados neste caso também foram descritas por Collacico et al. (2008), Crivellentin \& Borin-Crivelletin (2015), Gremski et al. (2014) e Ramos et al. (2015). A região da picada foi no membro pélvico, uma das regiões de maior ocorrência, segundo Brasil (2001). Vários avisos epidemiológicos sobre a prevalência de Loxosceles são encontrados na região sul e sudeste do Brasil, principalmente em São Paulo (onde ocorreu este caso), Paraná, Santa Catarina e Rio Grande do Sul (Brasil, 2001; Frezza, 2007). Segundo Torres et al. (2013), o verão é a época com maior frequência de casos, a mesma estação do acidente relatado neste caso.

Corroborando com o tratamento escolhido para o paciente do presente estudo, diversos autores afirmaram a eficiência do uso da rifamicina no tratamento de feridas cutâneas cirúrgicas ou feridas infectadas (Abaylı et al., 2017; Cardot et al., 1995; Köşüs et al., 2010). O poder de auxílio à cicatrização que o açúcar possui é bem descrito na literatura (Haddad et al., 1983; Mphande et al., 2007; Topham, 2002), inclusive associada à rifamicina (Cavazana et al., 2009; Rahal et al., 1979) como foi feito no paciente do presente relato.

Materiais hospitalares simples e baratos, como curativos de algodão seco, cobrem a ferida e absorvem o exsudado. No entanto, estes não aumentam o ambiente de cicatrização de feridas, e eles aderem à ferida e são dolorosos para remover (Mphande et al., 2007). Por esta razão, optou-se pelo uso de bandagem (e não algodão), junto à mistura de açúcar e rifamicina, aliados ao colar elisabetano. Na China antiga era comum o uso de moxabustão e acupuntura para o tratamento de feridas abertas (Pinto, 2012), de formas similares àquelas usadas neste paciente. Scognamillo-Szabó \& Bechara (2001) descreveram que essas técnicas vêm sendo utilizadas com sucesso para reduzir processos inflamatórios, estimular a cicatrização e regeneração tecidual com sucesso similar ao encontrado pelos autores do presente relato.

O diagnóstico de acidente aracnídeo dentro da Medicina Veterinária Tradicional Chinesa é Acúmulo de Calor por Calor Tóxico, um padrão de excesso, visto que o paciente possuía os sinais clínicos coincidentes com este padrão, como aparecimento agudo de feridas com eritema, edema, calor e dor, hipertermia, bolhas e pus, condizendo com as descrições de Limehouse \& Taylor-Lemehouse (2006), Clavey (1995), Xie \& Preast (2012), Lobo Júnior (2012), e Wu et al (2013). Clavey (1995) explica que a patogenia do edema na MVTC ocorre por uma diminuição no fluxo suave de Qi, pois o organismo consome o Yuan Qi, para tentar manter esse fluxo. Como é função do rim controlar a água e houve, consumo de Yuan Qi, esse órgão torna-se fraco energeticamente, exigindo mais do baço e pâncreas, que, por sua vez, controla os músculos e o Jin Ye, para sustentá-lo, causando também sua fraqueza. Isso faz 
com que a Água, que deveria fluir normalmente, se estagne, causando acúmulo de líquido no espaço intersticial. Xie \& Preast (2012) explicam que, devido ao calor tóxico, o calor se acumula nos músculos e ferve ou cozinha o Xue, de modo que este gradualmente se torna espesso e passa a circular lentamente, o que leva à sua estagnação e, depois, à estagnação de Qi. A estagnação de Qi e sangue podem se tornar calor, que faz os músculos se degenerarem e, eventualmente, causam feridas de ulceração e pus, como encontrado no paciente deste estudo. As estratégias de tratamento são várias, entretanto, Xie e Preast (2012) afirmam que as principais formas seriam eliminar o calor e as toxinas, ativar a circulação do sangue e dissolver a estagnação, estratégias empregadas neste estudo.

Os acupontos escolhidos pelos presentes autores, VG4, B23, B52 E VB25, tonificam o Yin e Yang geral e principalmente do rim, harmonizam a via das águas, aumentam a energia essencial e a essência (Jing) e tonifica o Qi do rim (Limehouse \& Taylor-Lemehouse, 2006; Lobo Júnior, 2012). Já o ponto $\mathrm{R} 1$ tonifica o rim e o Jing, estabiliza o rim, refresca o calor do sangue, faz limpeza do calor tóxico e do fogo (Xie \& Preast, 2012, Deadman et al. (2001)). O VG20, é um ponto de intersecção com o meridiano da bexiga e, além de outras funções, regula e harmoniza o Yang Qi do corpo, relaxa os músculos e tendões. O acuponto BP6 é o encontro de três Yin da perna, harmonizando, fortalecendo e tonificando o Qi do baço e pâncreas, também tonifica o Qi do Rim e o Jing, faz a circulação e tonifica o Qi e Xue, além de harmonizar a via das águas (Lobo Júnior, 2012).

Os acupontos utilizados no tratamento condizem com a sua função energética, com a forma de tratamento descrita por Xie \& Preast (2012) e são descritos em tratamentos de Calor Tóxico também por Limehouse \& Taylor-Lemehouse (2006), Lobo Júnior (2012), Xie \& Preast (2012) e Wu et al. (2013). Os acupontos Ba Feng, que foram utilizados no pé direito, exteriorizam as energias perversas, dispersam o Vento e o Vento-Calor perversos, leva a energia e a faz circular no membro (Limehouse \& Taylor-Lemehouse, 2006; Lobo Júnior, 2012), promovendo a volta da propriocepção no cão atendido no hospital da Fait em 3 sessões, enquanto em um relato de caso, o paciente recuperou a propriocepção em 6 semanas, segundo (Deadman et al., 2001; Dimitrova, 2017).

Para acidentes com Loxosceles, Crivellentin \& Borin-Crivelletin (2015) recomendam uso de antibióticos de amplo aspectro, cefalexina na dose de $30 \mathrm{mg} / \mathrm{kg}$ e uso de opioides, como morfina na dose de 0,5 a $1 \mathrm{mg} / \mathrm{kg}$, fluidoterapia com Ringer Lactato, hidrocortisona na dose de $50 \mathrm{mg} / \mathrm{kg}$, já que não é disponível o soro antiloxoscélico para a medicina veterinária. Os medicamentos utilizados estão de acordo com os autores, entretanto, para a fluidoterapia foi utilizado a $\mathrm{NaCl}$ a $0,9 \%$ ao invés do Ringer Lactato. Mörschbächer et al. (2012) utilizaram um protocolo parecido para a analgesia ambulatorial do animal: morfina $(0,5 \mathrm{mg} / \mathrm{kg})$ e dipirona $(25 \mathrm{mg} / \mathrm{kg})$. Neste estudo utilizou-se a mesma dose para a morfina e tramadol na dose de $3 \mathrm{mg} / \mathrm{kg}$, visto que o animal era errante e apresentava dor.

Relatou-se acidente aracnídeo em um cão (Collacico et al., 2008), com sinais clínicos parecidos ao do presente estudo, mas os autores optaram por tratamento ambulatorial, posterior debridamento cirúrgico e aproximação do tecido cutâneo após necrose total do tecido afetado. Neste caso, não houve em nenhum momento a necrose do tecido cutâneo. Pinto (2012) explica que a moxabustão ativa a circulação do tecido, fato este pode ter impedido a necrose tecidual.

Machado et al. (2009) relataram um cão com duas lesões em região lombossacral e região dorsal do tórax, evoluindo havia quatro dias. O tutor do animal informou que as lesões eram, inicialmente, púrpuras e sensíveis, com eritema e petéquias, que havia piorado e o tecido havia necrosado, relatou também que havia encontrado uma aranha marrom perto do local onde o cão dormia. Os parâmetros físicos do animal, entretanto, apresentavam-se normais, com exceção das lesões necróticas presentes na pele. Foi sugerido a cirurgia reconstrutiva para o tutor, mas este preferiu tratar a ferida por segunda intenção. O animal, então, foi tratado cefalexina $30 \mathrm{mg} / \mathrm{kg}$, VO, BID e com banhos de sabonete antisséptico contendo Ticlosan. $\mathrm{O}$ fechamento da ferida ocorreu em 2 meses. Comparativamente no caso relatado, a ferida ocludiu em menos da metade do tempo. As feridas, histórico e achados clínicos de Machado et al. (2009) condizem com Chatzaki et al. (2012), Dantas et al (2014) e Ramos et al (2015). Entretanto, os achados clínicos e o tratamento usando o presente caso foram diferentes; não houve necrose tecidual e o fechamento da ferida ocorreu em três semanas.

Com a utilização da acupuntura, moxabustão e curativos com açúcar misturado à rifocina, iniciou-se a formação de tecido de granulação a partir do quarto dia de tratamento e reepitelização durante a 
segunda semana, enquanto outros autores (Hussni et al., 2001) afirmam que usando apenas açúcar iodado para tratamento de feridas em equinos, este processo ocorreu no dia oito de tratamento. Ao final da terceira semana de tratamento obteve-se a cicatrização total da lesão. Pelo atendimento ambulatorial, dos curativos com açúcar junto à rifamicina e sessões diárias de acupuntura e moxabustão obteve-se a oclusão total da ferida e retorno da propriocepção em três semanas.

\section{Referências}

Abaylı, C., Kul, Y., Koten, M., Karasalihoğlu, A. R., Taş, A., Yağız, R., \& Bulut, E. (2017). Possible ototoxic effects of topical rifamycin application: an electrophysiological and ultrastructural study. Turkish Archives of Otorhinolaryngology, 55(3), 99. https://doi.org/10.5152/tao.2017.2391.

BRASIL. Ministério da Saúde (2001). Fundação Nacional de Saúde. Manual de Diagnóstico e Tratamento de Acidentes por Animais Peçonhentos. ( $2^{\mathrm{a}}$ ed.) Fundação Nacional de Saúde, Brasília.

Cardot, E., Tillie-Leblond, I., Jeannin, P., Facon, A., Breuil, K., Patte, F., \& Tonnel, A.-B. (1995). Anaphylactic reaction to local administration of rifamycin SV. Journal of Allergy and Clinical Immunology, 95(1), 1-7. https://doi.org/10.1016/S0091-6749(95)70145-1.

Cavazana, W. C., Simões, M. L. P. B., Yoshii, S. O., Amado, C. A. B., \& Cuman, R. K. N. (2009). Açúcar (sacarose) e triglicerídeos de cadeia média com ácidos graxos essenciais no tratamento de feridas cutâneas: estudo experimental em ratos. Anais Brasileiros de Dermatologia, 84(3), 229-236. https://doi.org/10.1590/S0365-05962009000300003.

Chatzaki, M., Horta, C. C., Almeida, M. O., Pereira, N. B., Mendes, T. M., Dias-Lopes, C., Guimarães, G., Moro, L., Chávez-Olórtegui, C., \& Horta, M. C. R. (2012). Cutaneous loxoscelism caused by Loxosceles similis venom and neutralization capacity of its specific antivenom. Toxicon, 60(1), 2130. https://doi.org/10.1016/j.toxicon.2012.03.007.

Clavey, S. (1995). Fluid physiology and pathology in traditional Chinese medicine. Churchill Livingstone.

Collacico, K., Melo, S. C. A., \& Ferrari, R. (2008). Acidente por Loxosceles em cão-relato de caso. Ensaios e Ciência: Ciências Biológicas, Agrárias e Da Saúde, 12(2), 179-195.

Crivellentin, L. Z., \& Borin-Crivelletin, S. (2015). Casos de rotina em medicina veterinária de pequenos animais. In MedVet. MedVet.

Dantas, A. E., Horta, C. C. R., Martins, T. M. M., Carmo, A. O., Mendes, B. B. R. O., Goes, A. M., Kalapothakis, E., \& Gomes, D. A. (2014). Whole venom of Loxosceles similis activates caspases$3,-6,-7$, and-9 in human primary skin fibroblasts. Toxicon, 84, 56-64. https://doi.org/10.1016/j.toxicon.2014.04.002.

Deadman, P. J. of C. M. P., Baker, K., \& Al-Khafaji, M. (2001). A Manual of acupuncture. : : Journal of Chinese Medicine Publications, 376-380.

Dimitrova, A. (2017). Introducing a standardized acupuncture protocol for peripheral neuropathy: a case series. Medical Acupuncture, 29(6), 352-365. https://doi.org/10.1089/acu.2017.1242.

Frezza, R. M. (2007). Atendimento fisioterapêutico após cirurgia reparadora de lesões por aranha marrom: relato de caso. Revista Brasileira Em Promoção Da Saúde, 20(2), 133-140. https://doi.org/10.5020/18061230.2007.

Gremski, L. H., Trevisan-Silva, D., Ferrer, V. P., Matsubara, F. H., Meissner, G. O., Wille, A. C. M., Vuitika, L., Dias-Lopes, C., Ullah, A., \& de Moraes, F. R. (2014). Recent advances in the understanding of brown spider venoms: From the biology of spiders to the molecular mechanisms of toxins. Toxicon, 83, 91-120. https://doi.org/10.1016/j.toxicon.2014.02.023.

Haddad, M. do C. L., Vannuchi, M. T. O., Chenso, M. Z. B., \& Hauly, M. C. de O. (1983). Uso do açúcar nas feridas infectadas. Revista Brasileira de Enfermagem, 36, 152-154.

Hayashi, A. M., \& Matera, J. M. (2005). Princípios gerais e aplicações da acupuntura em pequenos animais: revisão de literatura. Revista de Educação Continuada Em Medicina Veterinária e Zootecnia Do CRMV-SP, 8(2), 109-122. https://doi.org/10.36440/recmvz.v8i2.3131.

Hussni, C. A., Wludarski, A. R. L., Nicoletti, J. L. de M., Thomassian, A., Alves, A. L. G., Figueiredo, L. M. A. de, \& Curi, P. R. (2001). Comparaçäo entre timerosal, glicerina iodada e iodo 
polivinilpirrolidona com açúcar, na cicatrizaçäo de pele em eqüinos. Arquivo de Cências, Veterinária e Zoologia, 4(2), 109-118.

Janssens, L. A. A. (2008). Acupuntura na clínica de pequenos animais. In S. J. Ettinger \& E. C. Feldman (Eds.), Tratado de medicina interna veterinária: Doenças do cão e do gato. Guanabara - Koogan.

Köşüş, A., Köşüş, N., Güler, A., \& Çapar, M. (2010). Rifamycin SV Application to Subcutanous Tissue for Prevention of Post-Cesarean Surgical Site Infection. European Journal of General Medicine, 7(3), 269-276. https://doi.org/10.29333/ejgm/82867.

Limehouse, J. B., \& Taylor-Lemehouse, P. A. (2006). Conceitos orientais da acupuntura. Acupuntura Veterinária, 2, 76-90.

Lobo Júnior, J. E. S. (2012). Acupuntura na Prática Clínica Veterinária. São Caetano do Sul, Interbook Machado, L. H. A., Antunes, M. P. P., Mazini, A. M., Sakate, M., Torres-Neto, R., Fabris, V. E., Vailati, M. C. F., \& Lourenço, M. L. G. (2009). Necrotic skin lesion in a dog attributed to Loxosceles (brown spider) bite: a case report. Journal of Venomous Animals and Toxins Including Tropical Diseases, 15(3), 572-581. https://doi.org/10.1590/S1678-91992009000300017.

Mörschbächer, P. D., Garcez, T. N. A., Correa, R. K. R., Torres, V. N., \& Contesini, E. A. (2012). Acidente aracnídico em um cão: relato de caso. Revista Veterinária Em Foco, 9(2), 184-188.

Mphande, A. N. G., Killowe, C., Phalira, S., Jones, H. W., \& Harrison, W. J. (2007). Effects of honey and sugar dressings on wound healing. Journal of Wound Care, 16(7), 317-319. https://doi.org/10.12968/jowc.2007.16.7.27053.

Pinto, K. R. S. (2012). Aumento da produção leiteira em vacas através do uso da moxabustão. Universidade do Porto.

Rahal, F., Mimica, I., Pereira, V., \& Athie, E. (1979). O açúcar no tratamento local das infeccoes das feridas cirurgicas. Revista Paulista de Pediatria, 94(5-6), 132-133.

Ramos, R. F. M., Girelli, L. P., Toledo, D. W., Ragnini, J. M., Calcagnotto, F. N., \& Silva, J. B. (2015). Acidente loxoscélico. Revista Da AMRIGS, 59(2), 134-139.

Scognamillo-Szabó, M. V. R., \& Bechara, G. H. (2001). Acupuntura: bases científicas e aplicações. Ciência Rural, 31(6), 1091-1099.

Silva, P. H., Silveira, R. B., Appel, M. H., Mangili, O. C., Gremski, W., \& Veiga, S. S. (2004). Brown spiders and loxoscelism. Toxicon, 44(7), 693-709. https://doi.org/10.1016/j.toxicon.2004.07.012.

Topham, J. (2002). Why do some cavity wounds treated with honey or sugar paste heal without scarring? Journal of Wound Care, 11(2), 53-55. https://doi.org/10.12968/jowc.2002.11.2.26372.

Torres, S. M. F., Frank, L., \& Hargis, A. (2013). Advances in Veterinary Dermatology. Blacwell Publishinf.

Wen, T. S. (2011). Acupuntura clássica chinesa. Editora Cultrix.

Wu, H.-Z., Fang, Z.-Q., \& Cheng, P. (2013). Introduction to diagnosis in traditional Chinese Medicine (Vol. 2). World Scientific.

Xie, H., \& Preast, V. (2012). Medicina veterinária tradicional chinesa: princípios fundamentais. Medvep.

\section{Histórico do artigo:}

Recebido: 1 de abril de 2021

Aprovado: 4 de maio de 2021
Licenciamento: Este artigo é publicado na modalidade Acesso Aberto sob a licença Creative Commons Atribuição 4.0 (CC-BY 4.0), a qual permite uso irrestrito, distribuição, reprodução em qualquer meio, desde que o autor e a fonte sejam devidamente creditados. 